\title{
Determinants of Deep Integration: Examining Socio-political Factors
}

\author{
Laura Márquez-Ramos • Inmaculada Martínez-Zarzoso • \\ Celestino Suárez-Burguet
}

\begin{abstract}
This research has three main aims: firstly, to empirically analyse the determinants of different levels of integration by re-examining the evidence presented by Baier and Bergstrand (Journal of International Economics 64(1):29$63,2004)$ in the JIE 64 (1); secondly, to analyse the importance of additional factors, in particular socio-political factors; and thirdly, to analyse the dynamics of the EU integration process. The results show that although economic and geographical factors are the most important explanatory factors for the probability of regional integration agreement formation or enhancement, socio-political variables also contribute to explain the formation of regional integration agreements. Democracies and countries with a higher level of economic freedom are more likely to form or enhance RIAs.
\end{abstract}

\footnotetext{
We would like to thank Jeffrey Bergstrand and an anonymous referee for their helpful comments, and also participants in the European Trade Study Group conference held in Dublin and in the Atlantic Economic Conference held in New York. Financial support from the Spanish Ministry of Public Works and the Spanish Ministry of Science and Technology is gratefully acknowledged (P21/08 and SEJ 2007-67548).

L. Márquez-Ramos $(\bowtie) \cdot I$. Martínez-Zarzoso • C. Suárez-Burguet

Department of Economics and Institute of International Economics, Universitat Jaume I,

Campus del Riu Sec, 12071 Castellón, Spain

e-mail: 1marquez@eco.uji.es

I. Martínez-Zarzoso

e-mail: martinei@eco.uji.es

C. Suárez-Burguet

e-mail: celes@eco.uji.es

I. Martínez-Zarzoso

Ibero-America Institute for Economic Research, Universität Göttingen, Platz der Goettigen Sieben 3, Goettingen, Germany
} 
Keywords Regional integration agreements · European Union · Discrete choice models $\cdot$ Socio-political factors $\cdot$ Natural partners

JEL Classification F15 F F50

\section{Introduction}

A major concern in the traditional literature on the formation of free trade areas (FTAs) has been whether these areas generate welfare gains for the individual countries that engage in these processes. Since the 1950s (Viner 1950), many authors have contributed to this debate, especially in the 1990s when studies based on the gravity model proliferated (Frankel et al. 1995, 1996, 1998). However, none of this research has attempted to evaluate the determinants of FTA formation.

Only recently have Baier and Bergstrand (2004) developed the first theoretical and empirical analysis of the economic determinants of FTA formation. They provide an economic benchmark for future political economy models to explain the determinants of FTAs. They find evidence showing that pairs of countries will be more likely to form FTAs if they share the following characteristics: a) they are geographically close to each other, b) they are remote from the rest of the world, c) they are large and of a similar economic size, d) the difference of capital-labour between them is large and e) the difference of their capital-labour ratios is small compared to the rest of the world. Baier and Bergstrand (BB) only consider whether or not each pair of countries is involved in an FTA. Therefore the variable they attempt to explain is binary and takes the values zero and one. Baier and Bergstrand (2007) show the importance of treating FTAs as endogenous when the determinants of trade flows are analysed. They show that when the endogeneity of the FTA variables is taken into account in gravity models, their effect on trade flows is quintupled.

In this paper, we extend BB's work in three ways: firstly, we address the importance of additional economic, geographical and socio-political variables as determinants of regional integration agreements (RIAs). Secondly, we investigate the determinants of five different levels of integration between pairs of countries: Preferential trade agreement (PTA), free trade agreement (FTA), customs union (CU), single market (SM) and monetary union (MU). Finally, we analyse the dynamics of the European Union integration process.

We begin by estimating an ordered logit model (instead of a binary probit) with the same explanatory variables considered by $\mathrm{BB}$ to benchmark our extension to their original work. Then, the ordered logit is estimated with additional economic, geographical and socio-political variables. The economic variables we consider are economic size, income differences and factor endowment differences. Adjacency and landlocked status are added to BB's list of geographical variables. The sociopolitical variables are a shared language, political regime, level of economic freedom and tariff barriers.

We find that: (i) BB's results are fairly robust, although the coefficient signs are reversed for the $\mathrm{K}-\mathrm{L}$ difference variable with our database; (ii) the additional characteristics considered have a significant impact on the probability of an RIA being 
formed; (iii) socio-political factors are less important than economic and geographical factors, but still significant in explaining RIA formation or enhancement.

To our knowledge, only a few authors have studied the determinants of regional integration who take into account the degree of integration. Wu (2004) considered different levels of integration ranked across countries. However, her paper focuses on the role that political and economic uncertainty plays in explaining RIA formation and her results are not directly comparable to $\mathrm{BB}$ since she includes different explanatory variables in her model. Wu shows that countries' per capita income, democracy and geographical characteristics appear to be the best indicators of the probability of participation in a certain level of RIA in the period 1987-1998. Surprisingly, Wu (2004) does not consider the distance variable as a determinant of RIA formation. This omission may influence the results obtained for other variables since the model is not well specified. Endoh (2006) derived a theoretical framework to explain the incentives of countries to conclude an RIA. The author stated that "the economic and political characteristics of determining the existence or absence of PTAs are quite different from those of FTAs and CUs". ${ }^{1}$ Heterogeneity among RIAs is taken into account in the empirical analysis, in which two different dependent variables are considered (FTAs/CUs based on GATT Article XXIV and all the PTAs including other types of agreement based on the Enabling Clause). The methodology used to estimate is a binary logit model. Finally, Vicard (2006) relates economic and political integration, and proves that the determinants of regional integration differ according to the type of regional integration agreement. The heterogeneity in the nature of RIAs is introduced by taking into account two integration levels: shallow RIAs (PTAs and FTAs) and deep RIAs (CUs and CMs). The author runs three different binary probit models, one for all RIAs, one for shallow RIAs and one for deep RIAs. Unlike these authors, we take on a more difficult question: Why deeper integration?

The remainder of the paper is structured as follows. In Section 2 stylised facts in relation to the reasons why countries decide to engage in deeper economic integration are discussed. Section 3 presents the theoretical framework and the econometric model. Section 4 describes the data, the variables and the hypothesis to be tested. Section 5 discusses the estimation results. In Section 6, the model is estimated for an additional sample, including data for the EU-27 from 1999 to 2007, thus enabling dynamic issues to be also analysed. Finally, Section 7 presents the conclusions.

\section{Stylised facts}

Decisions concerning economic integration are controversial in most cases; there are global benefits, but they are unevenly distributed among winners and losers. The best real example of deep economic integration is the European integration process. Although the initial goal was to avoid undesirable wars within the continent, a much more ambitious vision was endorsed over the years, that being one of the main goals: the completion of the European Monetary Union (EMU). Deep integration of this

\footnotetext{
${ }^{1}$ Endoh 2006, page 769 .
} 
form has generated clear benefits to European citizens in terms of welfare and growth.

However, since the recent accession of ten new member states in 2004 and two more in 2007, the European Union (EU) has witnessed an intense discussion regarding its future. The central question of the debate is featured in the title of the report launched by the Constructing Europe Network (EU-CONSENT): "Wider Europe, deeper integration? A common theoretical framework". The main aim of the EU-CONSENT is to elaborate the scenarios and strategies for the future of European integration and to evaluate the costs and benefits of each of them, based on the triangle of deepening, widening and completing. Over the years, the EU has been considered a "club" with open membership, but as integration deepens, the entry conditions become more exhaustive. Although uniformity was a rule until recently, the monetary union as well as other specific agreements (Schengen agreement on border controls) were restricted only to some members.

The debate concerning deep integration is also open in North America (Campbell 2005) and Asia (Wyplosz 2006). In both cases the expected benefits of deeper integration are only seen as uncertain, whereas the political-costs are high.

\section{Theoretical framework and econometric model}

\subsection{The theory}

Although deep regional integration can proceed along different lines, according to McKinnon (1979) it should start with domestic goods market liberalisation, followed by external trade integration, and should proceed with domestic financial market liberalisation and international capital integration. We define the concept of "deeper regional integration" in relation to the level of economic integration stated by Viner (1950). Therefore, deeper RIAs are those involving a higher level of economic integration. This paper is related to recent research in regional integration that investigates why countries enter an RIA, although it also focuses on the question of why countries engage in deeper integration processes.

What are the reasons why countries engage in deeper integration? Until recently the research in this field focused on the effects of regionalism and disregarded the economic and political factors which explain the presence or absence of free trade agreements between pairs of countries. Baier and Bergstrand (2004) were the first authors to theoretically explain the likelihood of PTAs between pairs of countries using only economic and geographical factors. Mansfield et al. (2002) considered this problem from a political-economy point of view, and demonstrated that more democratic countries had displayed a greater likelihood of concluding PTAs than other countries. In addition, Endoh (2006) derived a theoretical framework to explain the incentives of countries to conclude an RIA. The author stated that the economic and political characteristics of determining the existence or absence of PTAs are quite different from those of FTAs and CUs. The author derives seven testable hypotheses, of which Hypothesis 3 states that the possibility of concluding a PTA by a pair of countries increases as their quality of governance ameliorates. 
Four categories of FTA determinants can be inferred from this theoretical framework: economic geography factors, intra-industry trade and inter-industry trade determinants and socio-political factors. They will all be considered in the empirical analysis.

\subsection{Econometric model}

Probit and logit models have often been used to model discrete choice phenomena (BenAkiva and Lerman 1985). In this context, a logit model is a discrete choice system interpreted as a particular case of a model, the dependent variable of which is subject to limited variability, is not continuous and takes a finite number of values (McFadden and Train 2000; Koppelman and Wen 1998). This type of system describes the behaviour of economic agents in terms of probability. The probability of a specific selection is assigned to a series of explanatory values. This series of values gathers the characteristics of decision-makers and/or the attributes of the various choice alternatives.

Multinomial logit or probit models are used when there are more than two alternatives. However, they fail to account for the ordinal nature of the dependent variable used in this research. We aim to model the choice of sequential binary decisions, the first consisting of a pair of countries that either sign a preferential trade agreement (PTA) or do not. Once a country comes to a bilateral agreement, the next decision will be whether to take a further step and go to a higher level of integration. Therefore, the model objective is to take a series of binary decisions, each consisting of the decision of whether to accept the current value or to "take one more". ${ }^{2}$ In this context, Amemiya (1975) describes a model that applies to ordered discrete alternatives, such as the number of cars owned by a household. This is based on the assumption of local (as opposed to global) utility maximisation. The decisionmaker stops when the first local optimum is reached. Economic agents must choose between two sequential options, and their selection depends on their characteristics and their environment. In accordance with the characteristics of our dependent variable, an ordered logit model was specified in our study.

The model is built around a latent regression in the same way as the binomial probit model. An observed ordinal variable, $\mathrm{Y}$, is a function of an unobserved latent variable, $\mathrm{Y}^{*}$, which represents the difference in utility levels from an action. The continuous latent variable $\mathrm{Y}^{*}$ has a number of threshold points, and the value of the observed variable $\mathrm{Y}$ depends on whether or not a particular threshold is crossed. In the present analysis we assume that five different integration levels can be reached, therefore the number of thresholds is five,

$$
\begin{aligned}
& Y_{i}=0 \text { if } Y^{*}{ }_{i} \leq \delta_{1 ;} Y_{i}=1 \text { if } \delta_{1} \leq Y^{*}{ }_{i} \leq \delta_{2 ;} Y_{i}=2 \text { if } \delta_{2} \leq Y^{*}{ }_{i} \leq \delta_{3} \\
& Y_{i}=3 \text { if } \delta_{3} \leq Y^{*}{ }_{i} \leq \delta_{4 ;} Y_{i}=4 \text { if } \delta_{4} \leq Y^{*}{ }_{i} \leq \delta_{5 ;} Y_{i}=5 \text { if } Y^{*}{ }_{i} \geq \delta_{5}
\end{aligned}
$$

where the $\delta$ s are the unknown parameters to be estimated. Threshold 1 denotes that a pair of countries engages in a PTA, threshold 2 denotes an FTA, threshold 3 is a CU, threshold 4 is an SM, and threshold 5 represents an MU.

\footnotetext{
${ }^{2}$ There are instances in which the RIAs are moribund, then countries can decide to "take one less". This is not the case in the data being looked at.
} 
The continuous latent variable is given by,

$$
\mathrm{Y}_{\mathrm{i}}^{*}=\sum_{\mathrm{k}=1}^{\mathrm{k}} \beta_{\mathrm{k}} \mathrm{X}_{\mathrm{ki}}+\varepsilon_{\mathrm{i}}=\mathrm{Z}_{\mathrm{i}}+\varepsilon_{\mathrm{i}}
$$

where $X_{k i}$ are the explanatory variables, $\beta_{\mathrm{k}}$ are the coefficients and $\varepsilon_{\mathrm{i}}$ is the random disturbance term that is assumed to be independent of $\mathrm{X}$ and has a logistic distribution.

The ordered logit model estimates,

$$
Z_{i}=\sum_{k=1}^{k} \beta_{k} X_{k i}=E\left(Y_{i}^{*}\right)
$$

Once the $\beta_{\mathrm{k}}$ parameter and the M-1 $\delta \mathrm{s}$ have been estimated, they can be used to calculate the probability that $\mathrm{Y}$ will take on a particular value. For example, when $M=6$,

$$
\begin{aligned}
& \operatorname{Pr}(Y=0)=\operatorname{Pr}\left(Z_{i} \leq 0\right)=\frac{1}{1+\exp \left(Z_{i}-\delta_{1}\right)} \\
& \operatorname{Pr}(Y=1)=\operatorname{Pr}\left(Z_{i} \leq \delta_{1}\right)-\operatorname{Pr}\left(Z_{i} \leq 0\right)=\frac{1}{1+\exp \left(Z_{i}-\delta_{2}\right)}-\frac{1}{1+\exp \left(Z_{i}-\delta_{1}\right)} \\
& \operatorname{Pr}(Y=2)=\operatorname{Pr}\left(Z_{i} \leq \delta_{2}\right)-\operatorname{Pr}\left(Z_{i} \leq \delta_{1}\right)=\frac{1}{1+\exp \left(Z_{i}-\delta_{3}\right)}-\frac{1}{1+\exp \left(Z_{i}-\delta_{2}\right)} \\
& \operatorname{Pr}(Y=3)=\operatorname{Pr}\left(Z_{i} \leq \delta_{3}\right)-\operatorname{Pr}\left(Z_{i} \leq \delta_{2}\right)=\frac{1}{1+\exp \left(Z_{i}-\delta_{4}\right)}-\frac{1}{1+\exp \left(Z_{i}-\delta_{3}\right)} \\
& \operatorname{Pr}(Y=4)=\operatorname{Pr}\left(Z_{i} \leq \delta_{4}\right)-\operatorname{Pr}\left(Z_{i} \leq \delta_{3}\right)=\frac{1}{1+\exp \left(Z_{i}-\delta_{5}\right)}-\frac{1}{1+\exp \left(Z_{i}-\delta_{4}\right)} \\
& \operatorname{Pr}(Y=5)=\operatorname{Pr}\left(\delta_{5} \leq Z_{i}\right)=1-\frac{1}{1+\exp \left(Z_{i}-\delta_{5}\right)}
\end{aligned}
$$

Hence, using the estimated value of $\mathrm{Z}$ and the assumed logistic distribution of the disturbance term, the ordered logit model can be used to estimate the probability that the unobserved variable $\mathrm{Y}^{*}$ falls within the various threshold limits.

The unknown coefficients and the thresholds can be estimated numerically by the maximum likelihood method, where the above probabilities are the elements of the likelihood function. The probability that a higher integration level is chosen increases if the $\beta \mathrm{s}$ are positive and the corresponding explanatory variable increases. This can be seen by calculating the derivatives of the cumulative probabilities:

$$
\frac{\partial \operatorname{Pr}\left(Y_{i} \leq M\right)}{\partial X_{k i}}=-\beta_{j} \frac{\exp \left(Z_{i}-\delta_{k}\right)}{\left(1+\exp \left(Z_{i}-\delta_{k}\right)\right)^{2}}
$$

Since the interpretation of the coefficients of this kind of model is unclear, a commonly used practice is to calculate the marginal effects associated with the probability of an RIA being formed or higher integration stages being established. They are given by:

$$
\frac{\partial \operatorname{Pr}\left(Y_{i}=M\right)}{\partial X_{k i}}=-\beta_{j}\left(\frac{\exp \left(Z_{i}-\delta_{k}\right)}{\left(1+\exp \left(Z_{i}-\delta_{k}\right)\right)^{2}}-\frac{\exp \left(Z_{i}-\delta_{k-1}\right)}{\left(1+\exp \left(Z_{i}-\delta_{k-1}\right)\right)^{2}}\right)
$$

One advantage of an ordered logit over an ordered probit model is its simplicity. However, it is subject to the Independence of Irrelevant Alternatives (IIA) property, 
which constitutes a tight limitation as all alternatives must follow an independent choice function. Selection pairs $P_{i} / P_{j}$ of alternative $i$ over $j$ are independent of whether third alternatives exist. The advantage of this condition is that it enables the introduction of new alternatives, such as new integration levels, without having to re-estimate the model. The difference between the estimated parameters must be the same, regardless of the number of alternatives that the economic agent faces. The disadvantage of this property is that alternatives must be perceived as distinct and independent.

The evaluation of this type of model differs from traditional models in certain ways. Even though the ratio of an estimated coefficient to its corresponding estimated standard error follows a t-Student distribution, the F test is not appropriate for these models. The most commonly accepted test is the Pseudo- $\mathrm{R}^{2}$, a scalar measure of the explanatory power of the model derived from the maximum likelihood ratio. ${ }^{3}$ This test is defined as:

$$
\rho^{2}=1-\frac{\log L_{u}}{\log L_{c}}
$$

Where: $\mathrm{L}_{\mathrm{u}}=$ the likelihood function of the model with explanatory variables.

$\mathrm{L}_{\mathrm{c}}=$ the likelihood function of the model without explanatory variables and only one constant.

$\rho^{2}$ lies between zero and one, and equals 1 when the model is a perfect predictor:

$$
P_{i}=F\left(X_{i} \beta\right)=\left\{\begin{array}{lll}
1 & \text { if } Y_{i}=1 \\
0 & \text { if } Y_{i}=0
\end{array}\right.
$$

$P$ takes value 0 if $\log \mathrm{L}_{\mathrm{c}}=\log \mathrm{L}_{\mathrm{u}}$, thus $\rho^{2}$ increases to 1 when $\log \mathrm{L}_{\mathrm{c}}$ rises in relation to $\log \mathrm{L}_{\mathrm{u}}$.

An alternative way to evaluate the goodness of fit of an ordered logit is to calculate the exp (log likelihood / number of observations) which is the geometric average of $\mathrm{P}\left(\mathrm{O}_{\mathrm{j}} / \mathrm{X}_{\mathrm{j}}\right.$, estimates), where $\mathrm{O}_{\mathrm{j}}$ and $\mathrm{X}_{\mathrm{j}}$ are the outcome and the explanatory variables for observation $\mathrm{j}$. This ratio shows the probability of obtaining a certain outcome conditional on the estimates. The higher the ratio is, the greater the explanatory power of the model will be.

The interpretation of coefficients in an ordered logit model also differs explicitly from other models. In discrete choice logit and probit models, the sign of the coefficients denotes the direction of switch, but its magnitude is difficult to interpret. For example, the positive coefficients corresponding to the characteristics of the individuals in the ordered logit model estimated in this paper increase the probability that a pair of countries will be observed in a higher integration category. However, negative coefficients increase the probability that a pair of countries will be observed in a lower integration category.

\section{Data, hypothesis and variables}

\subsection{The data}

The model is first estimated with the data of 66 countries from 1999, representing over $75 \%$ of world trade (see Table A.1, Appendix A in Márquez-Ramos et al 2009).

\footnotetext{
${ }^{3}$ Also known as the likelihood ratio index (LRI).
} 
Data on income are obtained from the World Development Indicators (2001). Distances are the great circle distances between economic centres. Data on capital labour ratios are obtained from the Penn World Tables. Data on bilateral exports are obtained from Statistics Canada (2001), and tariff barriers from the World Bank website. Information about geographical and language dummies is from the CIA (2003). The Economic Freedom Index was obtained from the Heritage Foundation, and the political regime, from the Freedom House. A more detailed description of data and sources is presented in Table A.2, Appendix A in Márquez-Ramos et al. (2009). Finally, the agreements considered to build the dependent variable are also listed in Márquez-Ramos et al. (2009) (Table A.3).

\subsection{Hypothesis and variables}

According to the underlying theory described above, and in the context of the discrete choice model, our first hypothesis is that a pair of countries will be more likely to form or enhance an RIA when the distance between them is small. We specify the distance variable as in BB. This variable is called "natural" as it is defined as the logarithm of the inverse of distance between trading partners.

A second hypothesis is that the probability of RIA formation or enhancement increases as the remoteness of a country or pair of countries from the rest of the world rises. For comparative purposes, we constructed the same remoteness variable used by BB. When a country is relatively far from its trading partners, it tends to trade more bilaterally with its neighbours, thereby increasing the probability of RIA formation.

The third hypothesis is that the larger the economic size of the trading countries, the greater the probability of RIA formation or enhancement will be. $\mathrm{RGDP}_{\mathrm{ij}}$ measures the sum of the logs of real GDPs of countries $i$ and $j$ in $1960 .{ }^{4}$

The fourth hypothesis is that the more similar the countries' economic size is, the higher the probability of RIA formation or enhancement will be. DRGDP ${ }_{i j}$ is the absolute value of the difference between the logs of real GDPs of countries $i$ and $j$ in 1960.

The fifth hypothesis is that the larger the countries' economic size outside the RIA is, the lower the probability of RIA formation or enhancement will be. However, the size of the rest of the world (ROW) measured by the ROW GDP varies only slightly in a cross-section of countries and has not been included in the regression. $\mathrm{BB}$ obtained a non-significant coefficient for this variable.

The sixth hypothesis is that the probability that a pair of countries will form or enhance an RIA is higher if there is a larger difference in their relative factor endowments since traditional comparative advantages will be further exploited. However, if intercontinental transport costs are low, this probability may also decrease at high levels of specialisation. This can be modelled by adding a quadratic term to the estimated equation. We use absolute differences in the capital stock per worker ratio $\left(\mathrm{DKL}_{\mathrm{ij}}\right)$ as a proxy for relative factor endowment differences, as in $\mathrm{BB} .{ }^{5}$ $\mathrm{SQDKL}_{\mathrm{ij}}$ denotes squared $\mathrm{DKL}_{\mathrm{ij}}$.

\footnotetext{
${ }^{4}$ Data are from 1960 to avoid the problems derived from the endogeneity of income in the estimated equation. The same applies to variables DRGDPij and DKLij.

${ }^{5}$ Data are for 1965 rather than 1960, since data on capital labour ratios is only available from 1965 onwards in the Penn World Tables data series. Baier and Bergstrand (2004) use data for 1960.
} 
The seventh hypothesis is that more democratic countries (democracy) display a greater likelihood of concluding RIAs than other countries, as stated by Mansfield et al. (2002).

The eighth hypothesis is that a pair of countries is more likely to form or enhance an RIA than if they have a higher level of economic freedom and if they speak a common language.

The ninth hypothesis is that interior countries (landlocked) as well as neighbouring countries (adjacency) will have a higher probability of engaging in an RIA, especially with coastal countries. However, when a landlocked country trades with partners located in another continent (unnatural partner), it will have higher transport costs than a coastal country.

Finally, the tenth hypothesis is that countries with higher levels of protection (tariff barriers) will have more incentives to create or enhance an RIA with other countries in order to lower (or eliminate) artificial trade barriers and to facilitate trade.

Supplementary economic, geographical and socio-political variables are added to the list of variables used by BB as determinants of RIAs (hypotheses 7-10). Landlocked status and adjacency are added to the list of geographical variables used by $\mathrm{BB}$. The socio-political variables considered are: tariff barriers, sharing a common language, the political regime (this variable takes a value of 1 when the political regime was a democracy in 1950), ${ }^{6}$ and the level of economic freedom. The economic freedom variable takes a value between 1 and 1.99 for free countries, 22.99 for mostly free countries, 3-3.99 for mostly non-free countries and 4-4.99 for repressed countries. According to the hypotheses above, tariffs, language and democracy are expected to have a positive sign, and economic freedom is expected to have a negative coefficient. ${ }^{7}$

Bilateral trade flows were initially added as an economic variable. Trade flows were expected to have a positive sign since more trade between countries indicates a strong relationship and dependence, and a reason to sign an RIA. However, due to the endogeneity problems found for bilateral trade, we chose to exclude this variable from the estimations. Magee (2003) provides one of the first assessments of the hypothesis that two countries are more likely to form a PTA if they are already major trading partners. He estimates a probit and a non-linear two-stage least squares model that considers trade flows to be endogenous in the second specification. Magee's results show that greater bilateral trade flows significantly increase the likelihood that countries will form a preferential trade agreement in every specification of the model.

In this paper, the model estimated is an ordered logit. Five different possible levels of integration between pairs of countries are considered to investigate the determinants of regional integration agreements.

\footnotetext{
${ }^{6}$ Data for this variable were only available for the years 1950 and 2000 . To avoid the problems derived from the endogeneity of democracy in the estimated equation, we used the data from 1950.

${ }^{7}$ Note that according to the definition of these variables, higher values imply lower economic freedom.
} 


\section{Estimation results}

\subsection{Ordered logit estimation ${ }^{8}$}

We estimate an ordered logit model consisting of a system of 5 equations with common coefficients for all the explanatory variables and with different constant terms. This is known as the proportional odds model.

In the second column of Table 1 (Model 1), an ordered logit is estimated with economic and geographical variables, the same variables included in BB (probit estimation). Model 2 to Model 4 in columns 3 to 5 of Table 1 are estimated for different sets of variables grouped as geographical and socio-political variables, and Model 5 includes all the variables. This sequential analysis enables us to find out the most important factors in promoting RIAs.

The results are similar in both probit and ordered logit models, ${ }^{9}$ although the logit ordered coefficients are higher in magnitude. In general terms, we can state that the probability of reaching a higher level of integration is higher than the probability of signing any type of RIA when no previous agreement exists between the trading countries. However, as stated above, there is no consensus on the interpretation of the magnitude of the coefficients estimated in discrete choice models.

Models 2 and 3 in Table 1 show the results of the geographical variables. All geographical variables are significant at $1 \%$, and natural, remoteness and adjacency have a positive signed coefficient, while the landlocked variable coefficient is negative. In Model 3 the interaction variable (landlocked*remoteness) is added to consider the ambiguous sign expected for the landlocked variable. The estimated coefficient shows a positive sign, indicating that the probability of reaching a higher level of integration increases for more remote continental trading partners when one of them is landlocked.

Model 4, in column five of Table 1, shows that all the socio-political variables are significant: democracy, higher levels of economic freedom and a common language promote RIA enhancement. The coefficient on tariffs is positive, thus showing that a higher level of protection increases the probability that a country pair will be observed in a higher category. However, in terms of goodness-of-fit, Pseudo R2 is very low.

Finally, Model 5 includes economic, geographical and socio-political variables. Some interaction terms were also added to allow for the possibility that the effect of some variables, namely remoteness and language, could be different for natural and unnatural patterns. In this model, remoteness presents a negative sign, indicating that remote countries have a lower probability of reaching higher levels of integration, while the variables adjacency, language and tariffs are not statistically significant.

The Akaike Info Criterion (AIC) shows that the best specification is that estimated in Model 5, where all the variables are considered. For the specification where only geographical variables are considered, the AIC is lower (1.542) than that

\footnotetext{
${ }^{8}$ The results obtained when a binary probit is estimated are shown in Márquez-Ramos et al. (2009)

${ }^{9}$ See Márquez-Ramos et al. (2009)
} 
Table 1 Ordered logit results for the probability of RIA formation or enhancement

\begin{tabular}{|c|c|c|c|c|c|}
\hline & Model 1 & Model 2 & Model 3 & Model 4 & Model 5 \\
\hline \multicolumn{6}{|l|}{ Economic variables } \\
\hline RGDP & $0.18^{\mathrm{a}}(6.89)$ & - & - & - & $0.13^{\mathrm{a}}(3.45)$ \\
\hline DRGDP & $-0.17^{\mathrm{a}}(-3.77)$ & - & - & - & $-0.31^{\mathrm{a}}(-6.14)$ \\
\hline DKL & $-0.26^{\mathrm{a}}(-3.34)$ & - & - & - & $-0.30^{\mathrm{a}}(-3.25)$ \\
\hline \multicolumn{6}{|l|}{ Geographical variables } \\
\hline NATURAL & $1.49^{\mathrm{a}}(10.95)$ & $0.84^{\mathrm{a}}(12.83)$ & $0.83^{\mathrm{a}}(12.54)$ & - & $2.31^{\mathrm{a}}(8.26)$ \\
\hline REMOTE & $0.31^{\mathrm{a}}(6.28)$ & $0.24^{\mathrm{a}}(9.35)$ & $0.23^{\mathrm{a}}(8.22)$ & - & $-2.21^{\mathrm{b}}(-2.40)$ \\
\hline ADJACENCY & - & $0.49^{\mathrm{a}}(2.87)$ & $0.47^{\mathrm{a}}(2.79)$ & - & $-0.08(-0.24)$ \\
\hline LANDLOCKED & - & $-0.63^{\mathrm{a}}(-5.92)$ & $-0.94^{\mathrm{a}}(-5.46)$ & - & $0.27(0.79)$ \\
\hline LANDLOCKED $^{c}$ REMOTE & & & $0.14^{\mathrm{b}}(2.36)$ & & $0.15(1.48)$ \\
\hline NATURAL ${ }^{c}$ REMOTE & & & & & $-0.32^{\mathrm{a}}(-2.89)$ \\
\hline \multicolumn{6}{|l|}{ Socio-political variables } \\
\hline LANGUAGE & - & - & - & $0.50^{\mathrm{a}}(4.73)$ & $-1.09(-0.43)$ \\
\hline DEMOCRACY & - & - & - & $1.55^{\mathrm{a}}(11.01)$ & $0.49^{\mathrm{b}}(2.32)$ \\
\hline ECONOMIC FREEDOM & - & - & - & $-0.51^{\mathrm{a}}(-2.65)$ & $-1.05^{\mathrm{b}}(-2.23)$ \\
\hline TARIFF BARRIERS & & & & $0.20^{\mathrm{b}}(2.46)$ & $0.14(0.76)$ \\
\hline NATURAL ${ }^{c}$ LANGUAGE & & & & & $0.05(0.18)$ \\
\hline Cut 1 & -3.41 & -5.87 & -5.79 & 1.38 & -14.82 \\
\hline Cut 2 & -2.71 & -4.9 & -4.82 & 2.13 & -14.01 \\
\hline Cut 3 & -1.8 & -4.18 & -4.11 & 2.56 & -13.23 \\
\hline Cut 4 & -1.58 & -3.86 & -3.78 & 2.83 & -12.91 \\
\hline Cut 5 & 0.38 & -2.64 & -2.57 & 3.95 & -10.41 \\
\hline McFadden's $\mathrm{R}^{2}$ & 0.3112 & 0.1297 & 0.1306 & 0.011 & 0.355 \\
\hline Log likelihood & -1040.8 & -3198.63 & -3195.60 & -2967.25 & -889.71 \\
\hline Exp (log likelihood / observations) & 0.4954 & 0.4635 & 0.4646 & 0.4324 & 0.5127 \\
\hline Akaike Info Criterion (AIC) & 1.418 & 1.542 & 1.539 & 1.681 & 1.363 \\
\hline Number of observations & 1,482 & 4,160 & 4,160 & 3,540 & 1,332 \\
\hline
\end{tabular}

${ }^{\text {a }}$ significance at $1 \%$

${ }^{\mathrm{b}}$ significance at $5 \%$

${ }^{\mathrm{c}}$ significance at $10 \%$

Z-statistics are in brackets. The dependent variable is a discrete variable that takes the value of 1, 2, 3, 4 and 5 when trading partners were integrated respectively into a PTA, FTA, CU, SM and MU in 1999, and 0 otherwise. The Huber/White/sandwich estimator of variance is used instead of the traditional calculation, therefore the estimation uses heteroscedasticity-consistent standard errors. Bilateral trade, exporter's and importer's tariff barriers and economic freedom are shown in natural logarithms

obtained in regressions including only socio-political factors (1.681). This appears to indicate that geographical variables are important determinants of RIA formation.

As stated above, the interpretation of the coefficients in an ordered logit does not inform of the magnitude of switch since we can only state that positive coefficients increase the likelihood that the country pairs will be observed in a higher category, and negative coefficients increase the likelihood that the country pairs will be observed in a lower category. A preferable interpretation of the 
ordered logit coefficients is in terms of the odd ratios. The exponentiated coefficients in the logit model, shown in Table 2, can be interpreted as odds ratios for a 1-unit change in the corresponding variable. The emphasis is on the ratio " $\operatorname{Exp}(\beta)$ ", which is the odds conditional on $\mathrm{x}+1$ divided by the odds conditional on $\mathrm{x}$. For example in Model $1,1.19$ means that the odds of being in a higher integration level increase by 1.19 if RGDP increases by 1 . The interpretation can also be made in terms of percentages: the $\exp (1.49)$ obtained in the "natural" variable in Model 1 means that the odds increase by $346 \%\left\{[\exp (1.49)-1]^{*} 100\right\}$ if the variable increases by 1 , therefore the odds of being part of the monetary union versus lower integration levels is $346 \%$ higher for a one-unit increase in the "natural" variable. Table 2 shows that, in Model 5, the most important determinant of an RIA is the "natural" variable, followed by democracy (1.64), landlocked (1.31), tariff barriers (1.15) and real GDP (1.13).

We also calculate semi-standardised ordered logit coefficients that control for the metrics of the independent variables to see whether any change occurs in the ordering of effects. The option of standardised coefficients to measure the relative strength of the effects of the independent variables is more appropriate in the current empirical application since some independent variables are measured in different units. Table 2 shows that when standardised coefficients are considered ( $\left.\mathrm{e}^{\wedge} \mathrm{bStdX}\right)$, the ordering of the effects changes slightly. In Model 5, the "natural" variable's standardised coefficient is 7.95 , and it is 1.43 for RGDP and 1.22 for democracy. Therefore, the natural variable is still the most important followed by real GDP and democracy.

In order to evaluate the probability that the dependent variable will have a particular value, we use cut-offs terms. From Eq. 1, the threshold parameters for Model 1 are given by:

$\mathrm{Y}_{\mathrm{i}}=0$ if $Y^{*}{ }_{\mathrm{i}} \leq-3.41 ; \mathrm{Y}_{\mathrm{i}}=1$ if $-3.41 \leq \mathrm{Y}^{*} \leq-2.71 ; \mathrm{Y}_{\mathrm{i}}=2$ if $-2.71 \leq \mathrm{Y}^{*}{ }_{\mathrm{i}} \leq-1.8$; $\mathrm{Y}_{\mathrm{i}}=3$ if $-1.8 \leq \mathrm{Y}^{*}{ }_{\mathrm{i}} \leq-1.58 ; \mathrm{Y}_{\mathrm{i}}=4$ if $-1.58 \leq \mathrm{Y}^{*}{ }_{\mathrm{i}} \leq 0.38 ; \mathrm{Y}_{\mathrm{i}}=5$ if $\mathrm{Y}^{*}{ }_{\mathrm{i}} \geq 0.38$

For example, when the trading partners are Argentina and Paraguay, we can calculate the probability associated with this pair of countries by computing $\mathrm{Z}_{\mathrm{i}}$ with the obtained coefficients in Model 1 and the corresponding data: ${ }^{10}$

$$
\begin{aligned}
& \operatorname{Pr}(Y=0)=0.2442 ; \operatorname{Pr}(Y=1)=0.1499 ; \operatorname{Pr}(Y=2)=0.2236 ; \operatorname{Pr}(Y=3)=0.0505 ; \\
& \operatorname{Pr}(Y=4)=0.2664 ; \operatorname{Pr}(Y=5)=0.0654
\end{aligned}
$$

Hence for Argentina and Paraguay, the most likely outcome is that they will form a single market. In fact, they have been members of Mercosur since 1995.

Our second example is Spain and France, a pair of trading partners that are members of the European Union. Our results indicate that the highest probability is that of the establishment of a single market. In 1999 these countries were already in the third phase of the European Monetary Union (EMU), since they fulfilled the convergence criteria established in the Treaty of Maastricht. However, our results most probably show that they were only in the EMU starting phase. When the sociopolitical variables are also considered (Model 5), then our results indicate that the highest probability is that of the establishment of a monetary union. ${ }^{11}$

\footnotetext{
${ }^{10}$ See Márquez-Ramos et al. (2009)

${ }^{11}$ See Márquez-Ramos et al. (2009)
} 
Table 2 Odds ratios for the ordered logit

\begin{tabular}{|c|c|c|c|c|c|c|}
\hline & & Model 1 & Model 2 & Model 3 & Model 4 & Model 5 \\
\hline \multicolumn{7}{|l|}{ Economic variables } \\
\hline \multirow[t]{3}{*}{ RGDP } & coef & $0.18^{\mathrm{a}}$ & - & - & - & $0.13^{\mathrm{a}}$ \\
\hline & $\mathrm{e}^{\wedge} \mathrm{b}$ & 1.19 & - & - & - & 1.13 \\
\hline & $\mathrm{e}^{\wedge} \mathrm{bStdX}$ & 1.65 & - & - & & 1.43 \\
\hline \multirow[t]{3}{*}{ DRGDP } & coef & $-0.17^{\mathrm{a}}$ & - & - & - & $-0.31^{\mathrm{a}}$ \\
\hline & $\mathrm{e}^{\wedge} \mathrm{b}$ & 0.84 & - & - & & 0.73 \\
\hline & $\mathrm{e}^{\wedge} \mathrm{bStd} \mathrm{X}$ & 0.74 & - & - & & 0.59 \\
\hline \multirow[t]{3}{*}{ DKL } & coef & $-0.26^{\mathrm{a}}$ & - & - & - & $-0.30^{\mathrm{a}}$ \\
\hline & $\mathrm{e}^{\wedge} \mathrm{b}$ & 0.77 & - & - & - & 0.74 \\
\hline & $\mathrm{e}^{\wedge} \mathrm{bStdX}$ & 0.75 & - & - & & 0.71 \\
\hline \multicolumn{7}{|l|}{ Geographical variables } \\
\hline \multirow[t]{3}{*}{ NATURAL } & coef & $1.49^{\mathrm{a}}$ & $0.84^{\mathrm{a}}$ & $0.84^{\mathrm{a}}$ & - & $2.31^{\mathrm{a}}$ \\
\hline & $\mathrm{e}^{\wedge} \mathrm{b}$ & 4.46 & 2.33 & 2.30 & - & 10.09 \\
\hline & $\mathrm{e}^{\wedge} \mathrm{bStd} \mathrm{X}$ & 3.89 & 2.10 & 2.08 & & 7.95 \\
\hline \multirow[t]{3}{*}{ REMOTE } & coef & $0.31^{\mathrm{a}}$ & $0.24^{\mathrm{a}}$ & $0.22^{\mathrm{a}}$ & - & $-2.21^{\mathrm{b}}$ \\
\hline & $\mathrm{e}^{\wedge} \mathrm{b}$ & 1.37 & 1.28 & 1.25 & - & 0.11 \\
\hline & $\mathrm{e}^{\wedge} \mathrm{bStdX}$ & 1.76 & 1.51 & 1.47 & & 0.02 \\
\hline \multirow[t]{3}{*}{ ADJACENCY } & coef & - & $0.49^{\mathrm{a}}$ & $0.47^{\mathrm{a}}$ & - & -0.08 \\
\hline & $\mathrm{e}^{\wedge} \mathrm{b}$ & - & 1.63 & 1.60 & - & 0.92 \\
\hline & $\mathrm{e}^{\wedge} \mathrm{bStdX}$ & - & 1.09 & 1.09 & & 0.99 \\
\hline \multirow[t]{3}{*}{ LANDLOCKED } & coef & - & $-0.63^{\mathrm{a}}$ & $-0.94^{\mathrm{a}}$ & - & 0.27 \\
\hline & $\mathrm{e}^{\wedge} \mathrm{b}$ & - & 0.53 & 0.39 & - & 1.31 \\
\hline & $\mathrm{e}^{\wedge} \mathrm{bStdX}$ & - & 0.77 & 0.68 & & 1.12 \\
\hline \multirow[t]{3}{*}{ LANDLOCKED $^{c}$ REMOTE } & coef & - & - & $0.14^{\mathrm{b}}$ & - & 0.15 \\
\hline & $\mathrm{e}^{\wedge} \mathrm{b}$ & - & - & 1.15 & - & 1.17 \\
\hline & $\mathrm{e}^{\wedge} \mathrm{bStdX}$ & - & - & 1.14 & & 1.16 \\
\hline \multirow[t]{3}{*}{ NATURAL ${ }^{c}$ REMOTE } & coef & & & & & $-0.32^{\mathrm{a}}$ \\
\hline & $\mathrm{e}^{\wedge} \mathrm{b}$ & & & & & 0.73 \\
\hline & $\mathrm{e}^{\wedge} \mathrm{bStdX}$ & & & & & 0.01 \\
\hline \multicolumn{7}{|l|}{ Socio-political variables } \\
\hline \multirow[t]{3}{*}{ LANGUAGE } & coef & - & - & - & $0.50^{\mathrm{a}}$ & -1.09 \\
\hline & $\mathrm{e}^{\wedge} \mathrm{b}$ & - & - & - & 1.65 & 0.33 \\
\hline & $\mathrm{e}^{\wedge} \mathrm{bStdX}$ & - & - & - & 1.19 & 0.67 \\
\hline \multirow[t]{3}{*}{ DEMOCRACY } & coef & - & - & - & $1.55^{\mathrm{a}}$ & $0.49^{\mathrm{b}}$ \\
\hline & $\mathrm{e}^{\wedge} \mathrm{b}$ & - & - & - & 4.69 & 1.64 \\
\hline & $\mathrm{e}^{\wedge} \mathrm{bStdX}$ & - & - & - & 1.61 & 1.22 \\
\hline \multirow[t]{3}{*}{ ECONOMIC FREEDOM } & coef & - & - & - & $-0.51^{\mathrm{a}}$ & $-1.05^{\mathrm{b}}$ \\
\hline & $\mathrm{e}^{\wedge} \mathrm{b}$ & - & - & - & 0.60 & 0.35 \\
\hline & $\mathrm{e}^{\wedge} \mathrm{bStdX}$ & - & - & - & 0.85 & 0.72 \\
\hline \multirow[t]{3}{*}{ TARIFF BARRIERS } & coef & - & - & - & $0.20^{\mathrm{b}}$ & 0.14 \\
\hline & $\mathrm{e}^{\wedge} \mathrm{b}$ & - & - & - & 1.22 & 1.15 \\
\hline & $e^{\wedge} b S t d X$ & - & - & - & 1.17 & 1.11 \\
\hline NATURAL ${ }^{\mathrm{c}}$ LANGUAGE & coef & & & & & 0.05 \\
\hline
\end{tabular}


Table 2 (continued)

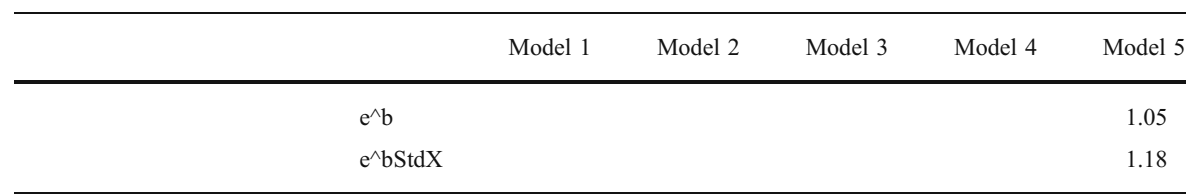

\footnotetext{
${ }^{a}$ significance at $1 \%$

${ }^{\mathrm{b}}$ significance at 5\%

${ }^{\mathrm{c}}$ significance at $10 \%$
}

Odd ratios are $\mathrm{e}^{\wedge} \mathrm{b}$ and $\mathrm{e}^{\wedge} \mathrm{bstdX} . \mathrm{e}^{\wedge} \mathrm{b}=\exp (\mathrm{b})=$ factor change in odds for unit increase in $\mathrm{X}$; $\mathrm{e}^{\wedge} \mathrm{bStdX}=$ $\exp (\mathrm{b} * \mathrm{SD}$ of $\mathrm{X})=$ change in odds for SD increase in $\mathrm{X}$. The dependent variable is a discrete variable that takes the value of 1, 2, 3, 4 and 5 when trading partners were integrated respectively into a PTA, FTA, CU, SM and MU in 1999, and 0 otherwise. The Huber/White/sandwich estimator of variance is used instead of the traditional calculation, therefore the estimation uses heteroscedasticity-consistent standard errors. Exporter's and importer's tariff barriers and economic freedom are shown in natural logarithms

The calculation of the predicted probabilities for all the trading partners ${ }^{12}$ shows that $69 \%$ of the agreements and $84 \%$ of the non-agreements were correctly predicted by the ordered logit model. Of all cases, $17 \%$ had excessive bilateralism, ${ }^{13}$ i.e., when the predicted level of integration was lower than the real level, and we found that bilateralism was insufficient for $6.5 \%$ of the trading partners.

\subsection{Marginal effects}

As BB point out, "one complication arises in estimating the partial effects on the response probabilities for the particular vector of RHS variables, $x$, in our model by using mean values for the levels. One of the RHS variables, REMOTE, is the product of a continuous variable and a binary variable (...) the mean value of this variable is economically meaningless". ${ }^{14}$

As we also use REMOTE, we estimate separately the marginal effects on the response probabilities with the mean value of REMOTE when the trading partners are in the same continent, and when REMOTE takes the value of zero (the trading partners are not in the same continent, they are unnatural partners).

To compare the effect of the RHS variables across different levels of integration, in Table 3 we estimate the marginal effects (for Model 5) for all the integration levels for both natural and unnatural partners. ${ }^{15}$

Table 3 shows different probabilities depending on the level of integration. For each level of integration, the probabilities are shown for natural and for unnatural partners. However, for the three last categories (customs union, single market and monetary union) the probabilities can only be calculated for natural partners since these integration levels are only reached by countries in the same continent. These

\footnotetext{
${ }^{12}$ According to Model 1.

13 "Excessive" and "insufficient" bilateralism are terms used by BB.

14 Baier and Bergstrand (2004), page 55.

${ }^{15}$ Dummy variables are not included since the mean values of these variables do not have an economic interpretation.
} 
Table 3 Response probabilities for natural and unnatural trading partners in Model 5 (evaluated at the mean level of remote and at remote $=0$ )

\begin{tabular}{|c|c|c|c|c|}
\hline \multirow{3}{*}{$\begin{array}{l}\text { Variable } \\
\text { NATURAL }\end{array}$} & \multicolumn{4}{|c|}{$Y i=\operatorname{Pr}($ Preferential Trade Agreement $\mid$ natural partners $)=0.167$} \\
\hline & \multicolumn{4}{|c|}{$\mathrm{dYi} / \mathrm{dx} \quad$ z-statistics $\quad 95 \%$ confidence interval } \\
\hline & -0.007 & -0.310 & -0.047 & 0.034 \\
\hline REMOTE & $3.373^{\mathrm{a}}$ & 5.770 & 2.227 & 4.518 \\
\hline RGDP & 0.000 & 0.190 & 0.000 & 0.000 \\
\hline DRGDP & $0.028^{\mathrm{a}}$ & 3.880 & 0.014 & 0.043 \\
\hline DKL & 0.009 & 0.540 & -0.025 & 0.043 \\
\hline ECONOMIC FREEDOM & $0.762^{\mathrm{a}}$ & 5.480 & 0.490 & 1.035 \\
\hline \multirow[t]{3}{*}{ TARIFF BARRIERS } & $-0.393^{\mathrm{a}}$ & -4.670 & -0.558 & -0.228 \\
\hline & \multicolumn{4}{|c|}{ Yi $=\operatorname{Pr}($ Preferential Trade Agreement $\mid$ unnatural partners $)=0.031$} \\
\hline & $\mathrm{dYi} / \mathrm{dx}$ & z-statistics & \multicolumn{2}{|c|}{$95 \%$ confidence interval } \\
\hline NATURAL & $0.071^{\mathrm{a}}$ & 6.950 & 0.051 & 0.091 \\
\hline RGDP & 0.000 & 0.510 & 0.000 & 0.000 \\
\hline DRGDP & $-0.004^{\mathrm{b}}$ & -2.040 & -0.008 & 0.000 \\
\hline DKL & $-0.019^{\mathrm{a}}$ & -5.250 & -0.026 & -0.012 \\
\hline ECONOMIC FREEDOM & -0.011 & -0.270 & -0.089 & 0.068 \\
\hline \multirow[t]{3}{*}{ TARIFF BARRIERS } & $0.052^{\mathrm{a}}$ & 3.140 & 0.019 & 0.084 \\
\hline & \multicolumn{4}{|c|}{ Yi $=\operatorname{Pr}($ Free Trade Agreement $\mid$ natural partners $)=0.189$} \\
\hline & $\mathrm{dYi} / \mathrm{dx}$ & z-statistics & \multicolumn{2}{|c|}{$95 \%$ confidence interval } \\
\hline NATURAL & -0.003 & -0.310 & -0.023 & 0.016 \\
\hline REMOTE & $1.587^{\mathrm{a}}$ & 2.910 & 0.518 & 2.657 \\
\hline RGDP & 0.000 & 0.190 & 0.000 & 0.000 \\
\hline DRGDP & $0.013^{\mathrm{a}}$ & 3.310 & 0.005 & 0.021 \\
\hline DKL & 0.004 & 0.540 & -0.012 & 0.020 \\
\hline ECONOMIC FREEDOM & $0.359^{\mathrm{a}}$ & 3.370 & 0.150 & 0.567 \\
\hline \multirow[t]{3}{*}{ TARIFF BARRIERS } & $-0.185^{\mathrm{a}}$ & -2.540 & -0.328 & -0.042 \\
\hline & \multicolumn{4}{|c|}{$\mathrm{Yi}=\operatorname{Pr}($ Free Trade Agreement $\mid$ unnatural partners $)=0.024$} \\
\hline & $\mathrm{dYi} / \mathrm{dx}$ & Z-statistics & \multicolumn{2}{|c|}{$95 \%$ confidence interval } \\
\hline NATURAL & $0.058^{\mathrm{a}}$ & 5.720 & 0.038 & 0.078 \\
\hline RGDP & 0.000 & 0.510 & 0.000 & 0.000 \\
\hline DRGDP & $-0.003^{\mathrm{b}}$ & -2.140 & -0.007 & 0.000 \\
\hline DKL & $-0.015^{\mathrm{a}}$ & -5.740 & -0.021 & -0.010 \\
\hline ECONOMIC FREEDOM & -0.009 & -0.270 & -0.073 & 0.055 \\
\hline \multirow[t]{3}{*}{ TARIFF BARRIERS } & $0.043^{\mathrm{a}}$ & 4.150 & 0.023 & 0.063 \\
\hline & \multicolumn{4}{|c|}{$\mathrm{Yi}=\operatorname{Pr}($ Customs Union $\mid$ natural partners $)=0.125$} \\
\hline & $\mathrm{dYi} / \mathrm{dx}$ & z-statistics & \multicolumn{2}{|c|}{$95 \%$ confidence interval } \\
\hline NATURAL & 0.000 & 0.330 & -0.002 & 0.003 \\
\hline REMOTE & -0.251 & -0.840 & -0.835 & 0.333 \\
\hline RGDP & 0.000 & -0.190 & 0.000 & 0.000 \\
\hline DRGDP & -0.002 & -0.820 & -0.007 & 0.003 \\
\hline DKL & -0.001 & -0.390 & -0.004 & 0.003 \\
\hline ECONOMIC FREEDOM & -0.057 & -0.850 & -0.188 & 0.074 \\
\hline
\end{tabular}


Table 3 (continued)

\begin{tabular}{|c|c|c|c|c|}
\hline \multirow[t]{3}{*}{ TARIFF BARRIERS } & 0.029 & 0.860 & -0.038 & 0.096 \\
\hline & \multicolumn{4}{|c|}{$\mathrm{Yi}=\operatorname{Pr}($ Single Market $\mid$ natural partners $)=0.381$} \\
\hline & $\mathrm{dYi} / \mathrm{dx}$ & z-statistics & \multicolumn{2}{|c|}{$95 \%$ confidence interval } \\
\hline NATURAL & 0.014 & 0.310 & -0.073 & 0.100 \\
\hline REMOTE & $-7.104^{\mathrm{a}}$ & -6.880 & -9.129 & -5.080 \\
\hline RGDP & 0.000 & -0.190 & -0.001 & 0.001 \\
\hline DRGDP & $-0.060^{\mathrm{a}}$ & -4.570 & -0.085 & -0.034 \\
\hline DKL & -0.020 & -0.540 & -0.091 & 0.052 \\
\hline ECONOMIC FREEDOM & $-1.606^{\mathrm{a}}$ & -6.920 & -2.061 & -1.151 \\
\hline \multirow[t]{3}{*}{ TARIFF BARRIERS } & $0.828^{\mathrm{a}}$ & 5.060 & 0.507 & 1.149 \\
\hline & \multicolumn{4}{|c|}{$\mathrm{Yi}=\operatorname{Pr}($ Monetary Union $\mid$ natural partners $)=0.027$} \\
\hline & $\mathrm{dYi} / \mathrm{dx}$ & z-statistics & \multicolumn{2}{|c|}{$95 \%$ confidence interval } \\
\hline NATURAL & 0.002 & 0.310 & -0.009 & 0.012 \\
\hline REMOTE & $-0.857^{\mathrm{a}}$ & -6.180 & -1.129 & -0.585 \\
\hline RGDP & 0.000 & -0.190 & 0.000 & 0.000 \\
\hline DRGDP & $-0.007^{\mathrm{a}}$ & -3.620 & -0.011 & -0.003 \\
\hline DKL & -0.002 & -0.550 & -0.011 & 0.006 \\
\hline ECONOMIC FREEDOM & $-0.194^{\mathrm{a}}$ & -4.540 & -0.277 & -0.110 \\
\hline TARIFF BARRIERS & $0.100^{\mathrm{a}}$ & 5.090 & 0.061 & 0.138 \\
\hline
\end{tabular}

${ }^{\text {a }}$ significance at $1 \%$

${ }^{\mathrm{b}}$ significance at $5 \%$

probabilities depend mainly on geographical, socio-political and economic variables, and their marginal effects differ across integration levels.

On the one hand, the results obtained for natural partners (countries in the same continent) indicate that when remoteness increases by $1 \%$, the probability of a PTA or an FTA being established increases by $337 \%$ and $159 \%$, respectively. However, the probability of a customs union or a higher integration agreement being established decreases with remoteness. This variable, together with socio-political factors, is the most influential factor on the probability of an RIA being formed or enhanced between natural partners.

Higher GDP differences increase the probability of PTA or FTA formation for natural partners, although the sign of the marginal effect for higher levels of integration is reversed, thus indicating that similarity of income, as expected, increases the probability that higher levels of integration (customs union, single market and monetary union) will be reached. The integration theory predicts that the costs of integration are lower when countries have similar levels of income and, consequently, a high level of intra-industry trade.

For unnatural partners however (countries in a different continent), the inverse of distance is the most important factor in PTA or FTA formation, and higher differences in income and in factor endowments lower the probability of a PTA or an FTA being established.

Finally, the results show the most likely outcomes are that natural partners will establish a single market and unnatural partners will not reach any agreement. When we order the probabilities for the various types of integration 
agreements from the highest probability to the lowest probability for natural partners, we obtain:

$$
\begin{aligned}
\operatorname{Pr}(\mathrm{SM} \text { or } 4) & =0.38 ; \operatorname{Pr}(\text { FTA or } 2)=0.19 ; \operatorname{Pr}(\text { PTA or } 1)=0.17 ; \operatorname{Pr}(\text { CU or } 3) \\
& =0.12 ; \operatorname{Pr}(\text { MU or } 5)=0.03
\end{aligned}
$$

These findings can seem surprising since the (conventionally assumed) second most integrated type of agreement, a single market, is the most likely type of RIA. An explanation is that the results obtained are likely to be dominated by the European Common Market.

\subsection{Sensitivity analysis}

We performed several robustness tests to validate our results. Firstly, the ordered logit model is based on the assumption of parallel slopes but this may be unrealistic, for example, if geographical variables are less relevant for higher integration levels. Therefore, the Brant test of the parallel regression assumption is used to validate the methodology used. The Brant (1990) test assesses whether or not the coefficients are the same for each category of the dependent variable. This produces Wald Tests for the null hypothesis that the coefficients in each independent variable are constant across categories of the dependent variable. Significant test statistics provide evidence that this assumption has been violated for most of the variables. With the exception of the capital-labour ratio, we cannot accept the equality of slopes for the different levels of integration (Table 4). These results indicate that we should estimate a generalised logit model, and they suggest what variables may be used in determining the thresholds. We therefore estimated a generalised ordered logit for all the regressions presented in Table 1. In some cases, the model did not converge, especially when the variables with missing data (K-L differences) were included. The results ${ }^{16}$ indicate that the geographical variables are significant and show the expected signs for the lower levels of integration (PTA, FTA), whereas these variables lose significance and decrease in magnitude for the higher levels. In contrast, the economic and political variables gain importance in the higher levels of integration.

Secondly, we re-estimated the ordered logit model with an alternative data set including 172 countries in 1998 taken from Magee (2003), which are available for replications on his web site. Our results confirm the sign and significance of the estimated coefficients for the income variables, the relative factor endowment differences and the natural variable. Contrary to $\mathrm{BB}$, the $\mathrm{K}-\mathrm{L}$ differences variable is negative and significant, thus validating our evidence. ${ }^{17}$

Thirdly, the observations are twice the number of country pairs. However, our dependent variable is symmetric and only trade and tariffs are asymmetric $\left(X_{i j} \neq X_{j i}\right)$. Therefore, we have re-estimated the model with only half the observations to check whether this would have affected the results. By taking $2145((66 * 65) / 2)$ country pairs, the results remained unchanged. ${ }^{18}$

\footnotetext{
${ }^{16}$ Results are available upon request from the authors.

${ }^{17}$ See Model 7.1 in Table 1 in Márquez-Ramos et al. (2009).

18 The results of taking into account the "repetition bias" in the 66-country sample are available upon request from the authors.
} 
Table 4 Brant test of parallel regression

\begin{tabular}{lrrr}
\hline Variable & \multicolumn{1}{c}{ chi2 } & $p>$ chi2 & df \\
\hline All & -336.22 & 1.000 & 20 \\
RGDP & 18.53 & 0.001 & 4 \\
DRGDP & 10.44 & 0.034 & 4 \\
DKL & 8.55 & 0.073 & 4 \\
NATURAL & 381.42 & 0.000 & 4 \\
REMOTE & 155.06 & 0.000 & 4 \\
\hline
\end{tabular}

A significant test statistic provides evidence that the parallel regression assumption has been violated

Fourthly, an additional robustness test has been performed. We checked whether the results were affected by the exclusion of an important economic bloc, such as the EU. The results excluding the EU countries also remained unchanged. ${ }^{19}$

Finally, the ordered nature of the dependent variable and the endogeneity of trade flows should ideally be considered simultaneously, although this is beyond the scope of this research.

\section{The dynamics of the European Union integration process}

The EU is the best real example of a successful integration process. However, the fact that the analysis in the previous sections focuses on data for 1999 implies that neither the entrance of 10 countries into the EU in 2004 nor the adoption of the Euro by Greece. ${ }^{20}$ In order to tackle the above-mentioned issues, the proposed model is also estimated for an additional sample, including data for the EU-27 from 1999 to 2007. A dynamic analysis would also be possible by adding the time dimension to the data.

In relation to the socio-political factors, democracy in 1950 was used in the previous section. Nonetheless, this variable may have very little to do with the probability of a country pair forming or enhancing an RIA during the period 19992007 in Europe. Although Spain and Portugal were dictatorships in 1950, both restored democracy in the mid-1970s, and joined the European Community (EC) in 1986. Greece also restored democracy in the mid-1970s and joined the EC in 1981. Hence, these three countries were democracies at the time they joined the EC. The same applies to the former socialist countries that joined the EU in 2004 and 2007. Therefore, unlike the analysis performed in Section 5, we take into account the political regime at the time of entry into the EC and not the situation in 1950. Instead of a dummy variable for democracy, the variable "polity" is used. ${ }^{21}$ Political rights and civil liberties at the time of entry into the EC have also been added to the list of

\footnotetext{
19 These results are available upon request from the authors.

${ }^{20}$ A referee kindly suggested the inclusion of this section in the paper.

${ }^{21}$ Annual data for democracy are obtained from the Polity IV dataset (http://www.systemicpeace.org/ inscr/p4v2007.xls). The variable POLITY2, which varies from -10 (strong dictatorship) to 10 (full democracy), is used in Section 6.
} 
political variables. They are measured on a one-to-seven scale, with one representing the highest degree of freedom and seven the lowest. ${ }^{22}$

Table 5 shows the results obtained for the EU-27 sample. In the second column of Table 5 (Model 6), an ordered logit is estimated with the same variables included in Model 1 (Table 1). ${ }^{23}$ Model 7 to Model 9, in columns 3 to 5 of Table 5 report the results for models with different sets of variables grouped as geographical and sociopolitical variables. Finally, Model 10 includes all the variables, as in Model 5 (Table 1).

Model 6 shows that the sign of the coefficients for the EU-27 sample is similar to the obtained for the 66-country sample (Model 1), although the coefficients are lower in magnitude. Model 7 shows the results when only geographical variables are included as regressors. All the geographical variables are significant at $1 \%$ and have the expected sign. Natural and adjacency have a positive-signed coefficient, while the landlocked variable coefficient is negative. Model 8 shows that all the sociopolitical variables are significant: "polity", the level of economic freedom (property rights and civil liberties) and the common language promote RIA enhancement. Model 9 includes an additional variable (tariff barriers), measuring the bilateral weighted tariffs between trading partners before accessing the EU-27. Unlike the results found in Table 1, the coefficient of this variable is negative, showing that a higher level of protection lowers the probability of a country pair being observed in a higher category in the European Union integration process. Model 10 includes economic, geographical and socio-political variables, excluding "polity" which correlates with the GDP. In this model, all the variables present the expected sign and are statistically significant. Model 11 includes a lagged dependent variable that indicates the previous integration level. This variable takes into account the fact that the probability of reaching an integration level depends on the point of departure (i.e., countries that do not have a previous agreement do not usually go straight into a monetary union). The results show that the probability of reaching a deeper integration level is higher if the countries already participate in an RIA.

Finally as in Baier and Bergstrand (2004), the previous specifications assumed that $R I A_{i j}$ is independent across observations. Since this assumption is not very realistic and could influence the estimation results, we followed the method proposed by Pesaran (2006) to account for interdependencies. This method consists in approximating the linear combinations of the unobserved factors by cross-section averages of the explained and explanatory variables and then running standard panel regressions augmented by the cross-section averages. This approach also yields consistent estimates when the regressors correlate with the factors. The results are presented in Model 12 and indicate that interdependencies matter (the added variables are statistically significant) but do not alter the sign of the estimated coefficients of the variables included in Model 10.

\footnotetext{
$\overline{22}$ Annual data on political rights and civil liberties are obtained from The Freedom House (2009): http:// www.freedomhouse.org/uploads/fiw09/CompHistData/FIW_AllScores_Countries.xls

${ }^{23} \mathrm{DKL}$ is not included in the analysis for the European integration process since DKL was not significant in the deepest integration levels (see Table 3). Remoteness is also calculated for the European country sample as was done in Baier and Bergstrand (2004), however, this variable is not included in the regressions since is not considered as comparable to the one constructed for the 66-country sample which includes unnatural partners.
} 
Table 5 Ordered logit results for the probability of RIA formation or enhancement. The European integration process

\begin{tabular}{|c|c|c|c|c|c|c|c|}
\hline & Model 6 & Model 7 & Model 8 & Model 9 & Model 10 & Model 11 & Model 12 \\
\hline \multicolumn{8}{|c|}{ Economic variables } \\
\hline RGDP & $0.13^{\mathrm{a}}(16.53)$ & - & - & - & $0.10^{\mathrm{a}}(10.52)$ & $0.05^{\mathrm{a}}(3.03)$ & $0.11^{\mathrm{a}}(10.50)$ \\
\hline DRGDP & $-0.09^{\mathrm{a}}(-6.13)$ & & - & - & $-0.11^{\mathrm{a}}(-7.30)$ & $-0.10^{\mathrm{a}}(-4.24)$ & $-0.12^{a}(-7.62)$ \\
\hline \multicolumn{8}{|c|}{ Geographical variables } \\
\hline NATURAL & $0.18^{\mathrm{a}}(6.40)$ & $0.21^{\mathrm{a}}(6.38)$ & - & - & $0.16^{\mathrm{a}}(4.48)$ & $0.12^{\mathrm{b}}(2.35)$ & $0.16^{\mathrm{a}}(4.74)$ \\
\hline ADJACENCY & - & $0.72^{\mathrm{a}}(7.49)$ & - & - & $0.61^{\mathrm{a}}(6.13)$ & $0.24^{\mathrm{c}}(1.92)$ & $0.61^{\mathrm{a}}(6.02)$ \\
\hline LANDLOCKED & & $-1.48^{\mathrm{a}}(-28.67)$ & & - & $\begin{array}{l}-0.82^{\mathrm{a}} \\
\quad(-15.48)\end{array}$ & $0.21^{\mathrm{b}}(2.40)$ & $\begin{array}{r}-1.03^{\mathrm{a}} \\
\quad(-17.87)\end{array}$ \\
\hline \multicolumn{8}{|c|}{ Socio-political variables } \\
\hline LANGUAGE & - & - & $1.82^{\mathrm{a}}(8.90)$ & $1.81^{\mathrm{a}}(8.97)$ & $1.29^{\mathrm{a}}(7.91)$ & $-0.17(-1.28)$ & $1.62^{\mathrm{a}}(10.55)$ \\
\hline POLITY & - & - & $0.96^{\mathrm{a}}(18.16)$ & $1.24^{\mathrm{a}}(20.22)$ & - & - & - \\
\hline $\begin{array}{l}\text { POLITICAL } \\
\text { RIGHTS }\end{array}$ & - & - & $-1.65^{\mathrm{a}}(-11.34)$ & $-1.76^{a}(-9.85)$ & $-1.50^{\mathrm{a}}(-11.64)$ & $-0.71^{\mathrm{a}}(-3.03)$ & $\begin{array}{l}-2.12^{\mathrm{a}} \\
(-12.79)\end{array}$ \\
\hline $\begin{array}{l}\text { CIVIL } \\
\text { LIBERTIES }\end{array}$ & & & $-2.12^{\mathrm{a}}(-26.17)$ & $\begin{array}{l}-1.47^{\mathrm{a}} \\
\quad(-17.56)\end{array}$ & $\begin{array}{l}-2.23^{\mathrm{a}} \\
\quad(-31.97)\end{array}$ & $0.09(0.99)$ & $\begin{array}{l}-1.50^{\mathrm{a}} \\
\quad(-19.10)\end{array}$ \\
\hline $\begin{array}{l}\text { TARIFF } \\
\text { BARRIERS }\end{array}$ & & & & $\begin{array}{l}-0.50^{\mathrm{a}} \\
\quad(-23.93)\end{array}$ & - & - & \\
\hline RIAij LAGGED & & & & & & $3.79^{\mathrm{a}}(37.23)$ & \\
\hline $\begin{array}{l}\text { AVERAGE } \\
\text { POLITICAL } \\
\text { RIGHTS }\end{array}$ & & & & & & & $2.11^{\mathrm{b}}(2.26)$ \\
\hline $\begin{array}{l}\text { AVERAGE } \\
\text { CIVIL } \\
\text { LIBERTIES }\end{array}$ & & & & & & & $1.53^{\mathrm{a}}(6.76)$ \\
\hline $\begin{array}{l}\text { AVERAGE } \\
\text { RIAij }\end{array}$ & & & & & & & $1.77^{\mathrm{a}}(20.07)$ \\
\hline Cut 1 & 1.72 & -5.53 & -0.46 & 0.82 & -5.93 & 2.76 & 5.04 \\
\hline Cut 2 & 4.54 & -2.52 & 4.00 & 6.74 & -2.31 & 10.07 & 8.89 \\
\hline Cut 3 & 4.75 & -2.29 & 4.19 & 6.99 & -2.00 & 10.78 & 9.27 \\
\hline Cut 4 & 6.51 & -0.39 & 6.33 & 9.58 & 0.25 & 18.00 & 11.75 \\
\hline McFadden's $\mathrm{R}^{2}$ & 0.03 & 0.06 & 0.16 & 0.27 & 0.16 & 0.62 & 0.21 \\
\hline Log likelihood & -8521.39 & -8149.07 & -5549.6761 & -4798.34 & -7265.16 & -2860.46 & -6878.55 \\
\hline $\begin{array}{l}\text { Exp (log } \\
\text { likelihood / } \\
\text { observations) }\end{array}$ & 0.27 & 0.29 & 0.35 & 0.40 & 0.33 & 0.61 & 0.35 \\
\hline $\begin{array}{l}\text { Number of } \\
\text { observations }\end{array}$ & 6,561 & 6,561 & 5,331 & 5,272 & 6,561 & 5,832 & 6,561 \\
\hline
\end{tabular}

\footnotetext{
a significance at $1 \%$

${ }^{\mathrm{b}}$ significance at $5 \%$

${ }^{\mathrm{c}}$ significance at $10 \%$
}

Z-statistics are in brackets. The dependent variable is a discrete variable that takes the value of 1, 2, 3, 4 and 5 when EU-27 trading partners were integrated respectively into a PTA, FTA, CU, SM and MU from 1999 to 2007 (There are not cases of PTA), and 0 otherwise. The Huber/White/sandwich estimator of variance is used instead of the traditional calculation; therefore the estimation uses heteroscedasticityconsistent standard errors. Bilateral trade, tariff barriers, polity, civil liberties and political rights are shown in natural logarithms 
As in Section 5, we evaluate the probability of the dependent variable having a particular value. Then we take the case of Spain and France ${ }^{24}$ in which our results for both the 66-country and EU-27 samples indicate that the highest probability is that of the establishment of a monetary union when socio-political variables were considered (Model 5 and Model 10, respectively).

\section{Conclusions}

In this paper, discrete choice modelling is used to study the determinants of regional trade agreements. An ordered logit model is estimated, in which geographical, economic and socio-political variables are considered as explanatory variables for RIA formation.

The results show that the probability of reaching a higher level of integration increases with income level, economic freedom, cultural affinities and remoteness, whereas it decreases with distance, income differences and factor endowment differences. Additionally, although economic and geographical variables seem to be the most important determinants of RIA formation, the socio-political factors considered are all statistically significant and their relative importance in explaining RIAs enhancement increases for higher integration levels and for natural partners.

The marginal effects, calculated for natural and unnatural trading partners, show that countries in the same continent (natural partners) will most probably establish a single market, whereas countries in different continents (unnatural partners) are most likely to not sign any agreement. This result is new in the RIA literature and should be validated by extending the sample to include more years and countries. The marginal effects also show that some variables, such as remoteness and differences in real GDP, have a positive influence on the formation of an RIA, but only for countries in the same continent and in the early stages of the integration process (PTA, FTA). However, when the categories considered are higher integration levels, the effect of these two variables is reversed. The marginal effect of economic freedom is not statistically significant for unnatural partners in the early stages of the integration process (PTA, FTA). However, it shows that a higher level of economic freedom has a positive influence on the enhancement of a RIA from a customs union to a single market and from a single market to a monetary union.

The estimation of a trade equation, that considers the formation of RIAs as an endogenously determined explanatory variable, remains an issue for further research.

\section{References}

Amemiya T (1975) Qualitative response models. Ann Econ Social Measurement 4:363-372

Baier SL, Bergstrand JH (2004) Economic determinants of free trade agreements. J Int Econ 64(1):29-63

\footnotetext{
${ }^{24}$ For the EU-27 country sample the probabilities are calculated in the year 1999 to be compared to those obtained in Section 5 with the 66-country sample.
} 
Baier SL, Bergstrand JH (2007) Do free trade agreements actually increase members' international trade? J Int Econ 71(1):72-95

Ben-Akiva M, Lerman S (1985) Discrete choice analysis. MIT, Cambridge

Brant R (1990) Assessing proportionality in the proportional odds model for ordinal logistic regression. Biometrics 46:1171-1178

Campbell B (2005) The case against continental deep integration. Paper presented to the Centre for Trade Policy and Law conference Options for Canada-US Economic Relations in the 21st Century, November 4, 2005

Central Intelligence Agency-CIA- (2003) The world factbook. From http://www.odci.gov/cia/publica tions/factbook

Endoh M (2006) Quality of governance and the formation of preferential trade agreements. Rev Int Econ 14(5):758-772

Frankel JA, Stein E, Wei S-J (1995) Trading blocs and the Americas: the natural, the unnatural, and the super-natural. J Dev Econ 47(1):61-95

Frankel JA, Stein E, Wei S-J (1996) Regional trading arrangements: natural or supernatural. Am Econ Rev 86(2):52-56

Frankel JA, Stein E, Wei S-J (1998) Continental trading blocs: are they natural or supernatural. In: Frankel JA (ed) The regionalization of the world economy. University of Chicago Press, Chicago, pp 91-113

Koppelman FS, Wen C (1998) Alternative nested logit models: structure, properties and estimation. Transp Res 32(3):289-298

Magee C (2003) Endogenous preferential trade agreements: an empirical analysis. Contrib Econ Anal Pol 2(1): $1-17$

Mansfield ED, Milner HV, Rosendorff BP (2002) Why democracies cooperate more: electoral control and international trade agreements. Int Organ 56:477-513

Márquez-Ramos L, Martínez-Zarzoso I, Suárez-Burguet C (2009) Determinants of the dynamics of the European Union integration process: an ordered logit approach, Universitat Jaume I, mimeo. In http:// works.bepress.com/inma martinez zarzoso/

McFadden D, Train K (2000) Mixed MNL models for discrete response. J Appl Econ 15(5):447-470

McKinnon R (1979) Money in international exchange: the convertible currency system. Oxford University Press, Oxford

Pesaran MH (2006) Estimation and inference in large heterogenous panels with multifactor error structure. Econometrica 74:967-1012

Statistics Canada (2001) World trade analyzer. The International Trade Division of Statistics of Canada

The Freedom House (2009) Freedom in the World Country Ratings 1972-2009. From http://www. freedomhouse.org/uploads/fiw09/CompHistData/FIW_AllScores_Countries.xls

Vicard V (2006) Trade, conflicts, and political integration: the regional interplays, CESifo Working Paper Series CESifo Working Paper No., CESifo GmbH

Viner J (1950) The customs union issue. Carnegie Endowment for International Peace, New York

World Bank (2001) World development indicators, Washington

Wu JP (2004) Measuring and explaining levels of regional economic integration. Working Paper B12/ 2004. Centre for European Integration Studies. From http://www.zei.de/

Wyplosz C (2006) Deep economic integration: is Europe a blueprint? Asian Econ Pol Rev 1:259-279 